\title{
Las voces rosarinas en el Colegio Libre de Estudios Superiores. Líneas y alcances de la participación de los profesionales e intelectuales de la ciudad de Rosario en la revista Cursos y Conferencias
}

Rosario voices in the Free College of Higher Education. Lines and scope of the participation of professionals and intellectuals of the city of Rosario in the magazine Cursos y Conferencias

Sandra Fernández

Universidad Nacional de Rosario/CONICET, Argentina

7acequias@gmail.com

\section{RESUMEN:}

La revista Cursos y Conferencias fue el órgano de difusión del Colegio Libre de Estudios Superiores. Considerables artículos en su extensa trayectoria fueron escritos por prestigiosos profesionales e intelectuales del medio rosarino. La meta de este artículo es en principio contextualizar tales contribuciones, en particular en torno de la generación de la filial Rosario de la institución. En segunda instancia, presentar a los colaboradores de la revista e interpretar la índole y alcances de sus participaciones.

Palabras clave: Revistas, Intelectuales, Cursos y Conferencias, CLES, Rosario.

\section{Abstract:}

The magazine Cursos y Conferencias was the prestigious organ of diffusion of the Free School of Superior Studies. Considerable articles in his extensive career were written by prestigious professionals and intellectuals of Rosario. The goal of this article is to contextualize such contributions, in particular around the generation of the Rosario branch of the institution. In the second instance, present the collaborators of the journal and interpret the nature and scope of their collaborations.

KEYWORDS: Magazines, Intellectuals, Cusos y Conferencias, CLES, Rosario.

1.

Aníbal Ponce creó en 1930 el Colegio Libre de Estudios Superiores (CLES). Ponce fue un prestigioso intelectual de izquierda, catalogado por la literatura académica como uno de los primeros marxistas latinoamericanos. El grupo fundador integrado por Roberto Giusti, Carlos Ibarguren, Alejandro Korn, Nicolás Laclau, Aníbal Ponce, Luis Reissig, Francisco Romero y Jorge Thénon amplió su base incorporando nombres del escenario científico e intelectual argentino. ${ }^{1}$

La meta del CLES era constituirse como un referente intelectual y académico. Para ello se nutrió de numerosos profesionales formados en las universidades públicas, quienes por aquellos años tenían dificultades para desplegar sus actividades en los claustros vernáculos. La labor desplegada se pensó desde una articulación entre el conocimiento y su transferencia al medio social, en donde lo popular y cultural no resultaran antagónicos con los saberes provistos desde el medio académico. Si bien se partía de una concepción alternativa y complementaria a los estudios universitarios, hubo un marcado esfuerzo por proponer un conjunto de cátedras libres, ${ }^{2}$ que de alguna manera replicaran un conjunto de contenidos, los cuales, incluidos en las currículas universitarias o no, representaban un balance de los debates intelectuales y científicos del momento. Los nombres requeridos para llevar adelante las cátedras libres fueron tanto docentes universitarios como reconocidos hombres de la cultura, la política y la economía (Fernández, 2019; Cernadas, 2006). 
A partir del impulso a ideales de izquierda y liberales reformistas, y la apuesta a una contundente lucha antifascista, el Colegio expresó un profundo compromiso político y una militancia intelectual en un contexto de carácter conservador. Por ello, desde sus inicios en la década de 1930, sus responsables se abocaron a crear filiales en distintos lugares de la geografía nacional, para poder desde allí convertirse en una alternativa en el medio social. Cuando en 1940, el CLES logra su personería jurídica, ${ }^{3}$ se aceleró la instancia de creación y consolidación de filiales. Las que más larga vida gozaron fueron las de Rosario y Bahía Blanca, pero por estos años pueden mencionarse también las de Comodoro Rivadavia, Río Gallegos, Córdoba, La Plata, Mendoza, Paraná, Santa Fe, Santiago del Estero y Tucumán. Aproximaciones como las de Mabel Cernadas (2006, pp. 605-618, 2005), Juliana López Pascual (2011, pp. 107-117), Héctor Guzmán (2013, pp. 59-65) y Sandra Fernández (2019, pp. 133-156) hacen posible un conocimiento más exhaustivo en torno del estudio de las filiales -Bahía Blanca, Santiago del Estero y Rosario respectivamente- en sus aspectos constitutivos y relacionales.

La revista Cursos y Conferencias hizo que el CLES fuera muy reconocido a nivel nacional e internacional. Desde sus páginas se creó un espacio de opinión y alta divulgación que propició la circulación del ideario progresista de la institución. La publicación de las disertaciones y cursos, tanto los realizados en Buenos Aires como en las filiales, nutrió de artículos a la novel publicación, ampliando la red de lectores y adherentes.

La creación de filiales tuvo una figura fundamental. Así, si Aníbal Ponce fue el mentor institucional del CLES - al que le imprimió una marca de gestión-, Luis Reissig fue el mejor intérprete del proyecto luego de la muerte de aquel. Su figura sería esencial como divulgador y administrador de la entidad, y en la configuración de una red que hizo posible la articulación de las numerosas filiales. En el caso particular de Rosario, su esmero en construir una red de contactos con figuras del medio local hizo posible el éxito del despliegue de la entidad. En tal ciudad, la filial se instaló formalmente en 1940. Las actividades se desplegaron en la sede del Círculo Médico, asociación profesional que reunía a la comunidad médica de la ciudad. ${ }^{4}$

El contacto más significativo fue Olga Cossettini, maestra y pedagoga reconocida nacional e internacionalmente, pero también hubo otros personajes ligados al ámbito de la cultura, la universidad, la política, y la economía. Según Fernández (2019, p. 36), el intercambio epistolar entre Luis Reissig y Olga Cossettini previo a la constitución de la filial muestra la estrategia de organizar reuniones para conformar un primer grupo de referencia, y dar densidad a la trama relacional agrupando a docentes universitarios, referentes de la cultura y de la educación, de entidades antifascistas, y a funcionarios, entre otros. Algunos de ellos se convertirán en asiduos colaboradores de la revista para acompañar el emprendimiento editorial.

2.

Existe una extensa bibliografía relativa al análisis de las publicaciones periódicas en las primeras décadas del siglo XX argentino, en la que se reconoce el impacto que las revistas literarias y culturales editadas a posteriori de la primera guerra mundial tuvieron en el contexto campo intelectual argentino. Son muy conocidas las ediciones que trazaron una hoja de ruta dentro de la literatura y el periodismo, pasando por zonas menos definidas como la estética, la historia, la pintura, la arquitectura y la ciencia. ${ }^{5}$ En estos años dos perspectivas se interceptaron, y en muchos casos colaboraron. Una influida por una línea literaria que, si bien tenía su origen en el movimiento modernista, se había mostrado capaz de trascenderlo y bucear por el universo de la vanguardia literaria con numerosísimas publicaciones. Otra, más heteróclita, vinculada a una faceta cultural de la producción escrita de nuestros intelectuales y sus influencias, que también se expresó en la escena nacional. La publicación de revistas de corte intelectual y cultural era un proceso que tenía proyección continental. Por ello fue un fenómeno que se manifestó también en países como México y Brasil, pero también con menor profundidad en Perú y Chile. 
En las décadas iniciales del siglo XX, la lectura y circulación de revistas había emprendido un discreto crecimiento, observable tanto en la variedad como en la tirada de publicaciones orientadas a un público que comenzaba a percibirse como heterogéneo, y al que las revistas se propusieron capturar a partir de distintas ofertas temáticas, así como también de una notable diversidad de estrategias discursivas y empresariales.

Tampoco es posible perder de vista que la aparición de una revista construye un espacio de legitimación, un campo de seducción y poder desde el cual extender una esfera de influencia nada despreciable en el plano del quehacer intelectual. Una revista se convierte en un órgano de difusión y divulgación idóneo para estructurar y reproducir formas de poder intelectual y político. Como afirma Diana Quattocchi-Woisson (1999, p. 55), no hay actividad profesional ligada al pensamiento que no necesite tener su propio canal de expresión; es sencillo detectar el reflejo corporativo en la aparición de toda publicación especializada. En una revista se promocionan libros, autores, cursos, conferencias; en una revista se estimulan y se "bendicen" cánones estéticos o epistemológicos a expensas de otros cánones estéticos y epistemológicos. Las manifestaciones de moda intelectual de época no son despreciables, sin embargo, lo que es constante en estos proyectos es la ambición de poder que signa la empresa, ya que para fundar una revista hay que estar convencido de tener algo original para decir y comunicar. El mensaje que se pretende enviar aparece como un operativo necesario que justifica esa tarea, pero hay otros móviles que, sin estar disimulados, no son siempre conscientes en quienes identifican la necesidad de una actividad cultural de esta índole.

En un contexto en el que la mayoría de las revistas literarias e intelectuales acostumbraban tener una vida muy breve -y además requerían del apoyo de medios de difusión complementarios-, es significativa la longevidad de algunas propuestas que, como en el caso de Cursos y Conferencias, superaron los veinte años. Creada y gestionada como uno de los pilares del Colegio, por sus páginas pasaron prestigiosos intelectuales, científicos, políticos y profesionales de distintos campos entre los años 1931 y 1952. La publicación, de carácter mensual, se propuso como centro de debate e intercambio cultural. Las temáticas que abordó fueron variadas, entre ellas, literatura, historia, geografía, psicología, ciencia, política. De alguna manera Cursos y Conferencias cristalizaba como referente de la cultura escrita el anhelo de constituir un espacio abierto a todas las cuestiones y preocupaciones de la vida nacional, para discutir y difundir temas de índole intelectual, científica y política que pudieran desarrollarse o no en el medio universitario. En muchos casos las propuestas editoriales tenían que ver directamente con lo ocurrido y debatido en las famosas Cátedras, y permitía exponer el resultado de investigaciones, ensayos, debates académicos y políticos. En la declaración de principios aparecida en el número inicial de la revista mencionada, los integrantes de la Comisión directiva establecían en forma precisa las características de la agrupación y fijaban la tarea a realizar:

Ni universidad profesional, ni tribuna de vulgarización, el Colegio Libre de Estudios Superiores aspira a tener la suficiente flexibilidad que permita adaptarse a las nuevas necesidades y tendencias. Germen modesto en favor de un esfuerzo a favor de la cultura superior, espera la contribución material, intelectual y moral de todas las personas interesadas en que aquellas sean un elemento de acción directa en el progreso social de la Argentina. ${ }^{6}$

Tal como afirman las colegas López Pascual (2011, pp. 107-117) y Carolina López (2017, pp. 120-130), esto permite referenciar de una manera particular la génesis y expansión de la revista, que se sostiene en esa frontera permeable y activa en la que lo académico y la alta divulgación se entrecruzan no solo a partir del contenido de los artículos, sino a partir de la forma que se elige para llevar ese proceso adelante; además, resulta muy significativo el tipo de los colaboradores que se brindan a realizarlo.

3.

A lo largo de las páginas de Cursos y Conferencias se registran muchas colaboraciones de referentes intelectuales, científicos y culturales, que, nacidos o emigrados, hacían de la ciudad de Rosario su lugar de acción profesional y creativa. 
El primer nombre de esta lista de colaboradores debe ser el de Olga Cossettini, en principio porque está tempranamente involucrada en la génesis de la filial en Rosario, de la que llegará a ser su secretaria, y luego, porque representa como ningún otro esta simbiosis entre el medio académico y el educativo.

Olga Cossettini fue una educadora fiel a los preceptos de la Escuela Nueva, que, desde su crítica al normalismo, transformó las prácticas escolares, y pasó a ocupar desde los años cuarenta un importante lugar dentro del mundo intelectual y cultural vernáculo. Su experiencia educativa, llevada adelante en la Escuela Carrasco - de carácter público y dependiente del Ministerio de Instrucción Pública y Fomento de la provincia de Santa Fe (MIPFSF)-, se coronó como una de las experiencias más significativas vinculadas al mundo pedagógico nacional en las décadas centrales de la pasada centuria. La "Escuela Serena" se desarrolló en un marco histórico singular. La propuesta tuvo su momento de esplendor vinculado a las gestiones de Pío Pandolfo (1937-38) y de Juan Mantovani (1938-1941), quienes fueron ministros de Instrucción Pública y Fomento de la provincia de Santa Fe durante el gobierno de la Concordancia. La experiencia pedagógica de Olga no pasó desapercibida en el mundo educativo nacional. Desde sus posiciones escolanovistas, Olga se distinguió por propiciar el trabajo educativo fuera de las aulas, el diálogo permanente entre el barrio y la escuela, el empleo del arte como recurso didáctico -la música, la pintura y la literatura-, la vinculación estética de los niños con el entorno y, fundamentalmente, la apuesta de enseñar a través del arte, propiciando que los niños y niñas se convirtieran en agentes de la cultura. La articulación de estos tópicos no solo se plasmaba en una organizada currícula escolar, sino en la puesta en marcha de las famosas "misiones culturales" 7 , y en lo que sería su corolario, la muestra artística "El niño y su expresión", de 1939. La muestra realizada en el Museo Castagnino de Rosario (MMBAJBC) fue junto con la posterior edición del libro del mismo nombre en 1940, por parte del MIPFSF, un hito en la proyección Cossettini (Fernández y Caldo, 2013, pp. 74-83).

La difusión del libro tuvo un fuerte impacto en el medio argentino y americano, lo que hizo de Cossettini una figura destacada y requerida. En ese contexto, Cossettini comienza a tener un acercamiento muy importante con el CLES, a través de Luis Reissig, lo que la lleva a participar de forma protagónica en la organización de la filial Rosario de la entidad. Olga es el nexo privilegiado para organizar las reuniones con los referentes rosarinos, y, si bien en un principio Cossettini deniega el ofrecimiento de Reissig para ser la secretaria de la filial en el momento de su génesis, lo sería en los años venideros, y así continúa esa fructífera relación. El vínculo y el respeto mutuo entre Reissig y Cossettini hicieron posible que la muestra "El niño y su expresión” viajara con su gestora a una exposición organizada en Buenos Aires. La actividad tuvo una amplia difusión en los medios, y se abrió con una conferencia inaugural en la Cátedra Sarmiento, insignia del CLES, en 1940 (Fernández, 2019, p. 44). Por ello, es de extrañar que Cossettini no tuviera más presencia en Cursos y Conferencias. Su colaboración en la revista estuvo vinculada a la coordinación del dossier referido a la educación rural. ${ }^{8}$ Cossettini prologa cuatro colaboraciones sobre el tema. Para ello reúne a maestros y funcionarios: Guido Miranda, maestro rural y representante de la Federación del Magisterio del Chaco, Alberto Maritano, destacado maestro autodidacta de Santa Fe, fundador de la Escuela Popular Sarmiento en la localidad de San Genaro y escritor; Domingo Bravo, maestro y director de escuela de Santiago del Estero; dos representantes de la Sociedad Gremial del Magisterio sanjuanino, Blanca Gutiérrez y Natale Francile; y Gumersindo Aguer, maestro y profesor de ciencias, director de escuela e inspector en la provincia de Entre Ríos. El germen había sido el curso organizado en el año 1947 en la filial Rosario del CLES, que, como bien dice Cossettini en su prefacio, se había realizado con el

...propósito de divulgación de la escuela rural argentina. (...) da a conocer el estado en el que se desenvuelve la escuela campesina (...) pero esta escuela es pobre, mal organizada, mal atendida (...) Existe un divorcio entre ella y el medio rural (...) El sistema feudal y el latifundio gobiernan vastas extensiones y la población campesina es su víctima.?

Otro colaborador rosarino en Cursos y Conferencias fue Ángel Guido. Guido estudió ingeniería en la Universidad Nacional de Córdoba, y fue, junto con Cortés Plá, uno de los estudiantes reformistas de 1918. Luego de su graduación en 1920 se instaló en su ciudad natal. Apenas creada la Universidad Nacional del 
Litoral (UNL) fue designado profesor titular de Historia de la Arquitectura I y II, y de Arquitectura II en la Facultad de Ciencias Matemáticas, Físico-Químicas y Naturales aplicadas a la Industria (FCM), actividad docente que continuaría en décadas posteriores. ${ }^{10} \mathrm{La}$ facultad -que al momento de su constitución tenía dos carreras, Agrimensura e Ingeniería civil-incorporó la de Arquitectura en junio de 1923, desde la cual Guido desplegaría una intensa actividad académica, ${ }^{11}$ que culminaría cuando fuera designado como rector de la UNL (1948-1950), por disposición del Poder Ejecutivo Nacional.

Guido trazaría además un derrotero que lo vincularía, desde su regreso a Rosario a comienzos de la década de 1920, a la vida cultural de la ciudad. Su ingreso en la Asociación Cultural "El Círculo" fue un hito. A su condición de socio le agregó rápidamente su actuación en la revista El Círculo, en la que escribió varios artículos entre los años 1924 y 1925, los cuales eran reflejo de una preocupación teórica ligada a la historia de la arquitectura. ${ }^{12}$ Desde esta faceta también tendría incidencia, ya durante la década de 1930, a través de su amigo y compañero Julio Marc, en el Museo Histórico Provincial (Montini, 2011, pp. 17-126; Príncipe, 2012, pp. 13-78). No solo diseñaría el edificio donde se elevó el museo, sino que se volcaría a colaborar en la estrategia coleccionista de la entidad ligada al arte americano (Fernández, 2013, pp. 248-256).

Profesionalmente abarcó todos los campos, desde el dibujo hasta el planeamiento urbano, sustentado todo ello en una vasta producción teórica. Sus diseños residenciales poblaron la ciudad y, especialmente durante la década del treinta, entre ellos se destacó primeramente su proyecto de Plan Regulador para Rosario de 1929 -realizó además el de Mar del Plata, Salta y Tucumán- y luego su proyecto "Invicta” para la construcción del Monumento a la bandera, proyecto que se hizo finalmente realidad con su inauguración en 1957.

Escribió distintos ensayos profundamente influidos por la obra de Ricardo Rojas, de quien fue amigo personal. En 1925 publicó una de sus obras fundamentales, Fusión hispano-indígena en la arquitectura colonial, publicada por la Casa del Libro. Allí recoge las ideas de Rojas al afirmar: "Urge poner dique a este abigarrado caos arquitectónico (...) no cabe otro camino para nuestra emancipación estética que la solución euríndica". Sus modelos, sin embargo, no fueron los modestos ejemplares del Río de la Plata. La atención se concentraría inicialmente en la arquitectura del núcleo cultural sudamericano, es decir, del altiplano peruano, y, en particular, en la magnífica y original arquitectura de Arequipa. Esta línea continuaría con otro texto de 1930, Eurindia en la arquitectura americana (Guido, 1930) que sería acompañado por otras colaboraciones en las que primeramente se trata de difundir el aporte fundamental de Heinrich Wölfflin a la comprensión del Barroco. En esa línea ensaya un análisis visual del Barroco español y del estilo hispanoincaico, en el cual ya señala la intromisión mudéjar en la arquitectura española -“anticlásica por temperamento”-, y demuestra luego la diversidad entre lo español y lo hispanoincaico (Cicutti y Nicolini, 1998, pp. 8-11). Entre su numerosa producción se destaca el texto Redescubrimiento en América del Arte (Guido, 1941), obra de 1941 que lo llevó a consolidar su reconocimiento en el medio internacional, el cual se venía construyendo desde hacía casi veinte años.

La línea estética que se trasunta los escritos de Ángel Guido responde a una fuerte reacción antipositivista y a sus derivaciones dentro de la "moderna filosofía del arte", lo que le permitiría legitimar su reivindicación y comprensión del arte americano a partir de conceptos claves derivados de esta línea de tratamiento, como la einfühlung o proyección sentimental, y la kunstwollen o voluntad de forma (Telesca, Malosetti y Siracusano, 1999; Funes, 1999). De aquí también la marcada decisión de invocar al "arte" como sustrato fundamental de identidad. A partir de los centenarios, en los que se buscó tanto un reencuentro con España como la consolidación obsesiva de las identidades nacionales, se propiciarían reflexiones en distintos puntos del continente acerca de la arquitectura colonial y su posible revitalización en el marco de la modernización. Ángel Guido se encontraría entre los nombres de quienes a través de conferencias y escritos organizarían un corpus teórico sobre la temática, como resultado de un proceso de "redescubrimiento" del Barroco y de las artes populares por parte de arquitectos y artistas, quienes, formados en los cánones modernos, comenzaban a mirar en otras direcciones. Varios arquitectos y artistas decidieron por esos años realizar viajes iniciáticos ${ }^{13}$ de descubrimiento de la génesis de la identidad americana. Guido, junto a su hermano Alfredo 
y al escritor Alcides Greca, se dirigió a Perú vía Chile en los primeros meses de 1920, viaje que consolidaría su consustanciamiento con lo indígena y colonial altoperuano (Gutiérrez Viñuales, 2016, pp. 5-6).

En 1930, Guido obtuvo el primer premio en la Exposición Panamericana de Arquitectos de Río de Janeiro, y fue nombrado miembro honorario del Instituto de Arquitectura de Río de Janeiro y La Habana respectivamente. En 1932 obtuvo la prestigiosa beca Guggenheim, y en la década siguiente fue designado doctor honoris causa de la Southern California University, de la Universidad de Quito y de la Universidad de Guayaquil; asimismo fue incorporado como miembro titular del Instituto Iberoamericano de Berlín, de la Société de Americanistes de París y de la Sociedad Central de Arquitectos de Uruguay. Su prestigio hizo que fuera invitado en numerosísimas ocasiones, en América y Europa, para dar conferencias, lo que le permitió construir una profusa red académica (Cicutti y Nicolini, 1998, pp. 42-46).

La polivalencia de Guido hizo además escribiera con el seudónimo de Onir Asor -rosarino al revés- una extraña novela simbólica que tituló La ciudad del puerto petrificado (1954).

Su participación en Cursos y Conferencias tiene que ver con su línea de trabajo académico y ensayístico ligada a la historia de la arquitectura y al arte mestizo americano, la que de alguna manera sintetiza la proyección que Guido tenía en el medio universitario como docente y en el medio internacional a través de sus premios y redes de interlocución. Todo ello además del reconocimiento que tenía gracias a su profusa producción escrita como ensayista y escritor, y a su vasta trayectoria profesional. El perfil profesional de Guido cuadraba con los presupuestos del CLES sobre sus colaboradores, por ello su participación será dilatada durante la década inicial de la revista. Publicará siete artículos: en 1931, "Arqueología y estética de la arquitectura criolla" ${ }^{14}$; "El ultrabarroco español y la arquitectura criolla" (I, 4) 3-4 ${ }^{15}$; "Densidad de forma y voluntad de forma” (I, 7 ${ }^{16}$. En 1934 publicará la saga "Génesis, apogeo y crisis del rascacielo" - probablemente como consecuencia de su viaje a Estados Unidos para la obtención de la Beca Guggenheim-, distribuida en los números 4, 5 y 7 de la revista Anatomía del rascacielo y de la catedral gótica, ${ }^{17}$ Morfología del rascacielo, ${ }^{18} \mathrm{y}$ Espíritu del rascacielo. ${ }^{19} \mathrm{Al}$ fin en 1944 participaría de la revista con "Arquitectura del siglo XIX". ${ }^{20}$ Además ya había publicado en 1930 un libro con el sello editorial del CLES: El arte de nuestro tiempo, (Rosario, 1930); y repetiría la experiencia con Catedrales y rascacielos (Buenos Aires, 1936).

Otro asiduo colaborador de la revista Cursos y Conferencias fue Cortés Colón Solís Plá, un ingeniero civil rosarino hijo de catalanes, que había participado del movimiento reformista del $1918,{ }^{21}$ y que desarrollaría su amplia actividad docente y académica desde la FCM de la UNL. En los inicios de su carrera en los años 20 fue docente en la Escuela Industrial Superior de la Nación y profesor titular de la cátedra de Construcción de la citada facultad. En 1922 asumió como consejero directivo; en 1925 alcanzó la titularidad de la cátedra Complementos de la Física General, y en 1934 fue electo decano por primera vez, cargo en el que fue elegido por unanimidad de los claustros en 1937 y 1940 respectivamente. Interrumpida su gestión por el golpe de 1943, vuelve a ser decano en 1945, para ser cesanteado en 1946 por la intervención de la UNL. Recupera su cargo de decano en 1955 y cierra su trayectoria universitaria siendo electo rector en 1962, período que sería nuevamente suspendido por el golpe militar de 1966 (Galles, 1997).

En el contexto histórico de la década del treinta, Plá se mostró muy interesado en mantener un fuerte contacto con el mundo de la ciencia argentina, especialmente con los científicos europeos exiliados. Figuras como Rey Pastor y Aldo Mieli fueron algunos de los representantes de este exilio científico europeo. Plá, como docente pero también como autoridad universitaria, se preocupó extensamente por mantener fluidos lazos con los profesionales exiliados, y aprovechar sus consejos y estímulos para potenciar la actividad académica de la FCM (Hurtado de Mendoza y de Asúa, 2002, pp. 137-159). Hay que señalar también que el impacto de la guerra civil española fue muy fuerte en la ciudad de Rosario, y que movilizó a amplios sectores de la política asociativa y partidaria, y a la sociedad en su conjunto. En el caso de las entidades asociativas ligadas a las distintas comunidades españolas, fue particularmente intensa la adhesión a alguno de los bandos en pugna. 
La posición de Cortés Plá fue muy clara; en 1937 había suscrito las declaraciones de la Conferencia Universitaria Internacional de París y de la Unión Sudamericana de Ingenieros, y otorgado mayor permanencia temporal a la residencia de los profesores extranjeros invitados. Además, se preocupó por establecer intercambios académicos con diferentes universidades extranjeras para prestigiar las cátedras de la UNL en Rosario. Tales vínculos se concretaron con la visita de Eugenio Darmois, Emanuel De Martonne y Paul Montel, profesores de la Sorbona, Leo Wherli de Suiza, Henry Michel de la Universidad de Bruselas, Julio Ricaldoni, Armando Acosta y Lara y Luis Giorgi, de la Universidad de Montevideo. ${ }^{22}$ Plá se manifestó públicamente entre sus colegas como antifranquista y partidario de la causa de las naciones aliadas durante la Segunda Guerra Mundial, mientras que en la FCM, profesores y estudiantes hicieron campaña en favor de los países aliados (De Marco, 2015, pp. 48-49). Esto se tradujo en una inserción institucional individual y colectiva de un espacio científico de Rosario, en un clima de discusión académica que había estado ausente hasta el momento, tanto en la UNL como en la ciudad de Rosario. Dos fueron los mecanismos, primero la creación del Instituto de Matemáticas de Rosario y luego una importante labor de producción y divulgación científica desatada por Cortés Plá, entre las que se encuentran sus colaboraciones en la revista Cursos y Conferencias. La revista publicó, en el año 1948, "La atomística y la responsabilidad social de los científicos”. ${ }^{23}$ Plá fue un reconocido autor, a su vasta producción editada por distintas revistas científicas de la época se le sumarían tres obras de divulgación científica de la colección Austral de Espasa Calpe: el primero, Galileo Galilei. Su vida y su obra (Buenos Aires, Espasa Calpe, 1942), prologado por Rey Pastor; el segundo, Isaac Newton (Buenos Aires, Espasa Calpe, 1945), prologado por Milei, y el tercero, Velocidad de la luz y relatividad. Con un apéndice con las memorias originales de Arago, Fizeau y Foucault, dedicado a Rey Pastor (Buenos Aires, Espasa Calpe, 1947). Existe otra obra de Plá, El enigma de la luz, publicada en 1948 por editorial Kraft, que está dedicada a la cuestión de la naturaleza de la luz, desde los griegos hasta la mecánica cuántica. Fue rescatada por Miguel de Asúa (2000, p. 245) como uno de los mejores libros sobre historia de la ciencia publicados en nuestro país.

La participación de Plá en Cursos y Conferencias respondió a una doble entrada: por un lado su estrategia académica de divulgación de su producción, que discutía no solo en el medio nacional sino también el internacional, y que lograba legitimidad en su campo profesional; por otro, la propuesta de incorporar la ciencia al debate político y social, perfil en el cual la revista del CLES pretendía transitar. En esto, además, no debe soslayarse su vinculación con el medio académico argentino, que hizo de la revista del CLES un lugar asiduo de discusión y publicación, desde donde entablaría una fuerte relación con referentes del mundo científico argentino, como los ya citados Rey Pastor, Mieli, y además Beppo Levi y José Babini.

Por su parte, Simón Marcelo Neuscholsz participó desde sus inicios en la fundación de la filial Rosario del CLES junto a Cossettini. Neuscholsz era un profesional de la medicina húngaro que había migrado a nuestro país. Radicado en Rosario se vinculó tempranamente con la Universidad Nacional del Litoral y creó la cátedra de Física Biológica a comienzos de los años 30. Durante el período y por su condición de exiliado se vinculó con diferentes instituciones antifascistas. La más significativa fue la Asociación de Intelectuales, Artistas, Periodistas y Escritores (AIAPE), cuya filial en Rosario dirigió. Neuschlosz fue un reconocido científico que publicaba entre otras revistas académicas la Revista Médica de Rosario (Neuchlosz, 1932), Cursos y Conferencias, Minerva (Neuchlosz, 1933). Tuvo una producción bibliográfica importante en idioma alemán y húngaro durante los años 20; ya en Argentina publicará a partir de 1937 de forma sistemática. ${ }^{24}$ Su preocupación por articular la comunicación de la ciencia con la especulación filosófica hizo que, por un lado, se encontrara muy relacionado con referentes del campo de las ciencias "duras", como Gaviola y Houssay, y, por otro, fuera muy cercano al medio intelectual y filosófico argentino, vinculándose con figuras como Francisco Romero y Mario Bunge. ${ }^{25}$ Las reuniones convocadas por el Colegio y por el MMBAJBC lo tendrían como un regular participante. Daría trece conferencias en el Museo, que luego serían compiladas en un libro que publicaría la Dirección de Cultura Municipal, dirigida por Manuel Castagnino (Neuschlosz, 1942). Su condición de referente se manifestaría en su sistemática convocatoria para llevar adelante las charlas 
inaugurales del CLES en Rosario durante $1931,{ }^{26}$ y sus colaboraciones serían incorporadas en distintos números Cursos y Conferencias. ${ }^{27}$ (Fernández, 2019).

Alcides Greca fue otro de los colaboradores rosarinos de la revista del Colegio. Si bien había nacido en San Javier, una población al norte de la ciudad capital provincial de estrecho contacto con los indígenas que allí vivían, desarrolló su extensa y variada actividad desde la ciudad de Rosario, donde murió en 1956. Había cursado estudios de Derecho en la Universidad Nacional de La Plata y tuvo una extensa actuación en la vida política argentina (como socialista en su juventud y posteriormente desde la línea yrigoyenista del radicalismo); se desempeñó como diputado y senador en el ámbito provincial y nacional, actividades por las que llegó a estar preso en varias ocasiones, entre ellas en Martín García en 1933. ${ }^{28}$ Desde allí escribiría, en 1934, que su obra siempre tendría un valor documental (Greca, 2018) y es ese rasgo el que lo acompañará como escritor, periodista y cineasta. Quienes rescatan su figura coinciden en afirmar que su actitud militante también recorrió su obra estética. Puede decirse que fue un intelectual tal como se lo concebía a finales del siglo XIX y principios del XX; formó parte del polifacético y selecto grupo que dedicaba buena parte de su tiempo a la literatura, el arte, la historia, el periodismo y la política de su época, mucho antes de la profesionalización de las disciplinas en el país (Greca, 2013; Coudannes, 2013, pp. 153-170). Con solo dieciocho años había fundado el diario El Mocoví en su San Javier natal, donde también escribió sus primeras obras en 1909. Ya en la ciudad de Santa Fe, funda y dirige los diarios El paladín del norte y La Palabra-este último predecesor de El Litoral-, y se dedica intensamente al activismo educativo y cultural. Por ejemplo, es uno de los impulsores de la organización de la Federación de Asociaciones Culturales, germen de la creación del Colegio Nacional y de la Escuela Normal Nacional en la ciudad de Santa Fe, así como uno de los que sostienen las sucesivas movilizaciones ligadas al activismo universitario, en particular en torno de la creación de la Universidad Nacional del Litoral (Rodríguez, 2013, pp. 3-4). La docencia universitaria fue otro de los aspectos más regulares de la vida de Greca, ya que como egresado de la carrera de Derecho de la UNLP accede a la cátedra de Derecho Administrativo y Derecho Municipal Comparado, en la Facultad de Ciencias Jurídicas y Sociales de la recientemente creada UNL, cargo que conservaría hasta su jubilación.

Su obra en prosa se abocó a visibilizar los procesos de cambio social y político de su época, los desequilibrios y conflictos regionales, el aporte del mestizaje a la identidad nacional o el lugar en la sociedad de los descendientes de los pueblos originarios, entre otros temas. En el contexto literario realista de las décadas del 20 y 30 su escritura se basó en criticar tanto al europeísmo como al criollismo, adhiriendo a la línea americanista en boga. La obra literaria incluye cuentos (Cuentos del comité, 1931), relatos de viaje (La torre de los ingleses, 1928) ${ }^{29}$, novelas (Viento norte, 1927 y La Pampa Gringa, 1935), relatos autobiográficos (Tras el alambrado de Martin García, 1934). ${ }^{30}$

La multifacética obra de Greca también transita el pensamiento urbanístico y territorial. Si bien en sus novelas subyace siempre una idea de paisaje siempre transversalizado por la problemática social, es en sus obras sobre planificación urbana en donde el gesto militante, de fuerte compromiso social, aparece. Su libro Problemas del Urbanismo en la República Argentina (1939), Derecho y Ciencia de la Administración Municipal, en el cual aborda desde los problemas de crecimiento urbano hasta las condiciones de vida en los pequeños poblados, es un excelente ejemplo de ello. Tal preocupación se arrastra aun hasta su obra tardía Una Nueva Capital para la Nación Argentina (1950), donde retoma las ideas fuerza trazadas por Juan Alvarez ${ }^{31}$ para analizar las disfuncionalidades políticas y sociales que provoca Buenos Aires como capital nacional, y, en tal sentido, expone la necesidad de una nueva capital; desarrolla hipótesis para su localización, sobre los estudios y ensayos previos sobre el tema (Rigotti, 2009; Mazza, 2013). Además de los que se fueron mencionando más arriba, se consideran los textos breves "Discurso aniversario Reforma Universitaria" (1938), "Intercambio intelectual entre los países de América” (1938), "Tragedia espiritual de los argentinos que hoy tienen 20 años” (1941). 
Pero quizás Greca es más conocido a partir de la película que filma en 1917, El último malón. El film de Greca aparece en la cinematografía argentina como una obra innovadora, que constituye una anomalía para su tiempo, en aspectos tanto cinematográficos como político-culturales, ya que se distancia del criollismo imperante para hacer eje en la situación de los pueblos originarios. El último malón, como otros filmes de época, da visibilidad a la conflictividad social rural y urbana en la segunda década del siglo XX, pero la singularidad de Greca se constituye al centrar su atención en los pueblos indígenas -específicamente los mocovíes de su localidad natal, San Javier- para retratar la rebelión que ellos mismos habían protagonizado en 1904. El guion que muestra a los mocovíes como objeto de explotación, opresión y discriminación por parte de la sociedad "blanca" permite relacionar al film y a su autor con ciertos antecedentes del indigenismo latinoamericano de los años veinte, lo cual es verdaderamente novedoso y significativo en el contexto de la época. La reconstrucción del levantamiento contó con la particularidad de que fue hecha con la participación de los propios indígenas que habían protagonizado el conflicto trece años antes, y también la de muchos "blancos" (criollos e inmigrantes) que habían sido testigos del mismo. Así, la película mostró por primera vez este significativo hecho de la historia local en la gran pantalla, por lo que se convirtió en una obra de gran valor cinematográfico, histórico y antropológico, que logró superar ampliamente sus alcances iniciales y que continúa vigente hasta nuestros días (Greca, 2014, pp. 35-52; Greca y Greca, 2012, pp. 127-148; Alvira, 2011-12,pp. 178). Greca asimismo publicó sistemáticamente en la Revista de Humanidades y Ciencias Sociales de la Universidad Nacional del Litoral, y en los distintos periódicos con los que se encontraba vinculado. En este último segmento se encuentra su colaboración con Cursos y Conferencias, donde, en 1939, publica "El complejo de inferioridad como factor de éxito" ${ }^{32}$ El texto es un ensayo literario sobre las manifestaciones de la pretendida "superioridad" de los sujetos. "El sarcasmo, la ironía, la frase que hiere como un dardo, surgen de individuos poseídos por el complejo de superioridad, pero que por circunstancias especiales han fracasado en la vida" ${ }^{33}$; esto afirmará Greca en su texto construido en clave periodística, al que compone como una catalogación moral de las actitudes del "superior" insatisfecho y resentido.

La participación de Ernesto Fábrega en el número de abril-mayo de 1941 de Cursos y Conferencias $^{34}$ no deja de asombrar. Fábrega es un hombre de negocios, con amplia trayectoria en el comercio de importaciónexportación (se había iniciado en 1916 como agente marítimo y despachante de aduana), propietario de una fábrica de bolsas de arpillera, miembro de la Bolsa de Comercio de Rosario desde 1919 hasta su muerte en 1966, y con una destacable participación en la Cámara del Yute (1937-1939). El artículo tiene que ver definitivamente con su experiencia como empresario, ya que la fabricación de bolsas de arpillera y el circuito de su comercialización se encontraban directamente relacionados con sus empresas y su participación en la principal corporación de la ciudad. Recordemos que, en esos momentos, una fracción de la exportación de cereales del país se embolsaba en los lugares de producción para luego ser embarcada en los puertos argentinos. El artículo de alguna manera transcribe su experiencia, adaptándola al formato didáctico de presentar cómo era la articulación entre el proceso de fabricación de las bolsas y la logística del circuito de comercialización y exportación del cereal. Fábrega se encontraba en los tres puntos del triángulo de la producción, circulación y comercialización: fabricaba las bolsas, comercializaba el cereal y regulaba la actividad a través de la cámara del sector en la bolsa de comercio: "Alabern y Fábrega compartían no solo la nacionalidad de origen, sino la condición de socios de la Bolsa y otras instituciones locales. En un momento determinado, dada la complementariedad de sus negocios, decidieron asociarse" ${ }^{35}$ Hay que señalar además que Fábrega presidió el directorio de otra importante corporación como la Unión Gremial, y de una entidad financiera, el Banco Popular de Rosario. Por otro lado, como otros miembros del grupo dominante local de la ciudad de Rosario, tuvo una labor destacada en el espacio público, en ámbitos como el asistencialismo, el asociacionismo cultural, el coleccionismo. 
4.

Como se ha observado a lo largo de estas páginas, los colaboradores rosarinos de Cursos y Conferencias, en su mayoría mantuvieron el perfil que la línea editorial de la revista imponía. En el caso de Guido, Plá, Neuscholsz y Greca, los cuatro eran profesores universitarios del UNL, comprometidos políticamente con el reformismo universitario, y con destacadas actuaciones en el espacio académico, público y político partidario. Cortés Plá tuvo una activa participación en la gestión universitaria, como decano y rector de la UNL, que fue acompañada con una militancia científica que lo llevó a organizar institutos señeros en la investigación regional, sobre la base de la protección de los científicos exiliados de Europa, y por una activa articulación con el medio científico argentino e internacional. Plá fue, además, un destacado divulgador científico que trascendió el espacio argentino. Simón Neuscholsz, médico emigrado, se integra rápidamente al medio rosarino. Era un académico del área de la medicina en la UNL, militante antifascista destacado por su intervención en entidades emblemáticas como la AIAPE, así como un inquieto divulgador a través de numerosos artículos y conferencias. Ángel Guido, más opaco en cuanto a su definición política, ${ }^{36}$ también es un personaje que expresa un compromiso muy fuerte con lo público, que se evidencia en su gestión cultural y su acción planificadora, pero también en su esfuerzo sistemático de explorar la cuestión teórica y ensayística, ligada al diseño y la arquitectura en América y vinculada al ideario del urbanismo racional. Su trayectoria, muy referenciada a nivel internacional, tiene al momento de la publicación de sus artículos en Cursos y Conferencias, un punto de inflexión. Greca, es el más colorido de los participantes; su vasta producción se encuentra atravesada por una actitud militante en la que se unifican el escritor y el político, el académico y el urbanista, el periodista y el cineasta, y así su poderoso deseo de abordar las problemáticas de su tiempo y el deseo de pronunciarse públicamente sobre ellas.

Las participaciones de Cossettini y Fábrega se encuentran más distantes de la tónica de autores ligados al medio universitario, pero son muy diferentes entre sí. Olga Cossettini, reconocida como un referente del escolanovismo -y legitimada en los círculos intelectuales y académicos por su experiencia condensada en el libro Elniño y su expresión, y por su viaje a los Estados Unidos por la Beca Guggenheim-, se muestra en Cursos $y$ Conferencias con lo que era su marca: la cuestión pedagógica. Sin embargo, no solo aporta la mirada sobre una de las problemáticas de la praxis escolar ligada a los desafíos de la educación rural, sino que presenta en la palestra de la edición a personajes que se encontrarían al margen de los presupuestos profesionales exigidos por la publicación. Cossettini introduce en el elenco de autores a una serie de maestros y maestras no solo comprometidos con su profesión sino con la participación gremial, y con la transformación pedagógica. El caso de Fábrega es más inorgánico a los objetivos propuestos por la publicación. Es complejo arriesgar una interpretación sobre la salida del artículo referido al uso de las bolsas en la comercialización del cereal. Quizás el texto es fruto de las redes de sociabilidad provistas por el clima de época, la solidaridad institucional en pos de generar filiales, o las tramas opacas de circulación de conocimiento y legitimidad.

Al fin estos colaboradores son un fiel espejo del interesante clima intelectual, cultural y educativo que transitaba la sociedad rosarina de las décadas del 20, 30 y 40. En aquel momento, las experiencias y prácticas de los involucrados distaba mucho de encuadrarse en una única línea ideológica e intelectual, lo que permitía observar las transferencias y mutaciones que se registraban no solo entre el propio grupo rosarino, sino, además, las ocurridas a partir de la cristalización de redes que eran abrumadoramente más elásticas y transversales que las que pueden observarse exclusivamente desde las miradas concentradas en el proceso porteño.

\section{BibLiOgRAFíA}

Alvira, P. (2012). “Una legión de espectros”: la cuestión indígena en El Último Malón. Anuario, (24), 169-186. 
Antequera, F. (2017). La mirada performativa y la construcción de la visualidad en el relato de viajes La torre de los ingleses (1929) de Alcides Greca. Cuadernos del CILHA, (26), 107-134.

Bisso, A. (2005). Acción Argentina. Un antifascismo nacional en tiempos de guerra mundial. Buenos Aires: Prometeo. Bisso, A. (2007). El antifascismo argentino. Selección documental y estudio preliminar. Buenos Aires: CEDINCI.

Bisso, A. y Celentano, A. (2006). La lucha antifascista de la Agrupación de Intelectuales, Artistas, Periodistas y Escritores (AIAPE) (1935-1943). En H. Biagini y A. Roig (Ed.), El pensamiento alternativo en la Argentina del siglo XX. Tomo II, Obrerismo, vanguardia, justicia social (1930-1960) (pp. 235-266). Buenos Aires: Biblos.

Cernadas, M. (2005). Una propuesta cultural alternativa para la región en la década del cuarenta: el Colegio Libre de Estudios Superiores en Bahia Blanca. Problemáticas sociopoliticas y económicas del Sudoeste Bonaerense. En Actas de las III Jornadas Interdisciplinarias del Sudoeste Bonaerense. Bahía Blanca: Universidad Nacional del Sur/ Archivo de la Memoria de la Ciudad de Bahía Blanca.

Cernadas, M. (2006). El entramado cultural de Buenos Aires desde las páginas de Cursos y Conferencias. En H. Biagini y A. Roig (Ed.), El pensamiento alternativo en la Argentina del siglo XX. Tomo II, Obrerismo, vanguardia, justicia social (1930-1960) (pp. 605-618). Buenos Aires: Biblos.

Cicutti, B., y Nicolini, A. (1998). Ángel Guido, arquitecto de una época en transición. Cuadernos de Historia IAA, (9), 7-58.

Coudanes Aguirre, M. (2013). Alcides Greca y su aporte a la construcción de identidades. Anuario de la Escuela de Historia Virtual, 4(4), 153-170. https://doi.org/10.31049/1853.7049.v0.n4.8392

Cutruneo, J. (2015). Arquitectos y mercado inmobiliario: vivienda e innovación tipológica. Rosario, 1920-40. Rosario: UNR Editora.

De Asúa, M. (2000). Isis y la historia de la ciencia en Argentina. En M. Monserrat (ed./coord.), La ciencia en Argentina entre siglos. Textos, contextos e instituciones (pp. 241-259). Buenos Aires: Manantial.

De Marco, M. (h) (2008). Las empresas centenarias de Rosario y su región. Revista de la Bolsa de Comercio de Rosario, (20), 48-60.

Fernández, S. (2000). Juan Álvarez y la ciudad que no pudo ser. Ensayo histórico y análisis comparativo de la historia local y regional desde el texto Buenos Aires. En G. Dalla Corte y E. Sonzogni (ed./coord.), Intelectuales rosarinos entre dos siglos: Serafin, Clemente y Juan Álvarez. Identidad local y esfera pública (pp. 191-219). Rosario: Prohistoria \& Manuel Suárez Editor.

Fernández, S. (2013). Sociabilidad, arte y cultura. Una experiencia en la Argentina de entreguerra. História Unisinos, 17(3), 248-256. http://dx.doi.org/10.4013/htu.2013.173.05

Fernández, S. (2019). Olga Cossettini y el Colegio Libre de Estudios Superiores (Argentina) 1939-1940. Historia y Sociedad, (36), 133-159.

Fernández, S. y Caldo, P. (2013). La maestra y el museo. Gestión cultural y espacio público. 1939-1942. Rosario: Secretaría de Estado de Ciencia, Tecnología e Innovación de la provincia de Santa Fe -SECTeI-, El Ombú Bonsai.

Funes, O. (1999). La Kustwille y la segunda emancipación americana. En Europa y Latinoamérica. Artes visuales y música, III Jornadas de Estudios e Investigaciones, Instituto de Teoría e Historia del Arte "Julio E. Payró". Buenos Aires: U.B.A.

Galles, C. (1997). Cortés Plá, Una vida universitaria. Rosario: UNR Editora.

Guido, A. (1941). Redescubriendo América en arte. Rosario: UNL.

Guido, A. (1930). Eurindia en la arquitectura americana. Santa Fe: UNL.

Greca, A. (2018) Cuentos del Comité. Espacio Santafesino. Recuperado de http://www.espaciosantafesino.gob.ar/up loads/archivos/ediciones_catalogo/greca-cuentos-del-comite.pdf.

Greca, A. (1909). Palabra de pelea. La Plata.

Greca, A. (1910). Sinfonía del cielo. Lágrimas Negras. La Plata.

Greca, D. (2014). De la historia en el cine al cine en la historia: potencialidades como documento del film El último malón. Páginas, 6(10), 35-52. 
Greca, D. (2015). Historia, novela y teatro. la representación del indígena en dos obras literarias de Alcides Greca. Estudios del ISHIR, 5(13), 120-149.

Greca, D. (2015). Representaciones de la alteridad: una aproximación a la imagen del indígena en el cine y la literatura de Alcides Greca. Seminario Regional, Carrera de Historia, FHYA-UNR, Rosario: mímeo.

Greca, V. y Greca, D. (2012). Un abordaje interdisciplinar de un relato cinematográfico: aproximación a la película El último malón (1917) desde la Antropología y la Historia. Claroscuro, (11), 127-148.

Gutiérrez Viñuales, R. (2016). Barroco americano y contemporaneidad. Persistencias, resignificaciones, escenarios (1810- 1945). En I. Rodríguez Moya, M.A. Fernández Valle y C. López Calderón (Eds.), Arte y patrimonio en Iberoamérica: tráficos transoceánicos (pp. 321-341). Castellón: Universitat Jaume I.

Guzmán, H. (2013). El Colegio Libre de Estudios Superiores frente al peronismo en Santiago del Estero 1950-1951. La razón histórica. Revista hispanoamericana de Historia de las Ideas, (24), 59-65.

Lafleur, H., Provenzano, S. y Alonso, F. (1968). Las revistas literarias argentinas. 1893-1967. Buenos Aires: CEAL.

López Pascual, J. (2011). Intelectuales: cartas, redes e instituciones. El archivo epistolar del Colegio Libre de Estudios Superiores de Bahía Blanca en el cruce de la Historia y la Antropología (1941-1952). Revista de Estudios Maritimos y Sociales, (4), 107-117.

López, C. (2017). Roberto Giusti: Relaciones culturales, vínculos personales. Sociabilidad intelectual en la Primera mitad del S. XX. En M. Cernadas, M. N. Agesta y J. López Pascual (Eds.), Amalgama y distinción. Culturas politicas y sociabilidades en Babia Blanca (pp. 102-130). Bahía Blanca: Ed. UNS.

Manzoni, C. (2004). Las formas de lo nuevo en el ensayo: Revista de Avance y Amauta. Revista Iberoamericana, $L X X(208-209), 735-747$.

Mazza, C. (2013). El pensamiento urbanístico y territorial de Alcides Greca. En Actas VII Encuentro de Docentes e Investigadores de la Historia del diseño, la arquitectura y la ciudad. Rosario: SCyT-UNR.

Montini, P. (2011). Ángel Guido y la colección de arte colonial del Museo Histórico Provincial de Rosario. En P. Montini y G. Siracusano (ed./coord.), Anales del Museo Histórico Provincial de Rosario. Rosario.

Neuschlosz, S. (1942). El hombre y su mundo a través de los siglos, historia de la evolución del pensamiento humano. Trece conferencias. Rosario: Dirección Municipal de Cultura.

Neuschlosz, S. (1939). Análisis del conocimiento cientifico. Buenos Aires: Losada.

Neuschlosz, S. (1939). La medicina como ciencia y como actividad social. Buenos Aires: Losada.

Neuschlosz, S. (1933). Las bases físico-quimicas de los fenómenos vitales. Rosario: Lagos y Cia.

Neuchlosz, S. (1932). La universidad ideal. A propósito, y al margen de un libro de Flexner. Revista Médica de Rosario, XXI(7), 534-550.

Pasolini, R. (2005). Intelectuales antifascistas y comunismo durante la década de 1930. Un recorrido posible: entre Buenos Aires y Tandil. Estudios Sociales (26), 81-116.

Pasolini, R. (2013). Los marxistas liberales: Antifascismo y cultura comunista en la Argentina del siglo XX. Buenos Aires: Sudamericana.

Prieto, A. (1968). Diccionario básico de literatura argentina. Buenos Aires: CEAL.

Rivera, J. (1995). El periodismo cultural. Buenos Aires: Paidos.

Rivera, J. (1998). El escritor y la industria cultural. Buenos Aires: Atuel.

Romano, E. (1984). Las revistas argentinas de vanguardia en la década de 1920. Cuadernos Hispanoamericanos, (411).

Príncipe, V. (2012). Cómo fundar un museo. La construcción de un espacio institucional para el arte. En P. Montini y otros. De la Comisión Municipal de Bellas Artes al Museo Castagnino: la institucionalización del arte en Rosario, 1917-1945 (pp. 13-78). Buenos Aires: Fundación Espigas.

Ramacciotti, K. y Cabrera Fisher, E. (2010). Un subsidio científico trunco. Bunge y la Asociación Científica para el progreso de la ciencia. Res Gestae, (48), 153-176. 
Rigotti, A. M. (2009). De la ciudad al territorio, del municipio a la nación: las promesas del urbanismo como alternativa tecnocrática de gestión 1920/1958. Jornadas Elites Intelectuales y formación de Estado, Universidad de San Andrés, Buenos Aires.

Rodríguez, A. (2013). Alcides Greca (1916-1930). Un intelectual entre la politica y la intervención cultural. XIV Jornadas Interescuelas/Departamentos de Historia. Mendoza: Universidad Nacional de Cuyo.

Salvador, N. (1962). Revistas argentinas de vanguardia (1920-1930). Buenos Aires: Facultad de Filosofía y letras, UBA.

Tarcus, H. (2004). Revistas, intelectuales y formaciones culturales izquierdistas en la Argentina de los 20. Revista Iberoamericana, $L X X(208-209), 749-772$.

Telesca, A. M., Malosetti, L., y Siracusano, G. (1999). Impacto de la moderna historiografía europea en la construcción de los primeros relatos de la historia del arte argentina. En (In)disciplinas: estética e historia del arte en el cruce de los discursos. XXII Coloquio Internacional de Historia del Arte. México: UNAM.

\section{Notas}

1 Para algunos autores, entre ellos Ricardo Pasolini (2013, p. 55; 2005, pp. 81-116), resulta una tesis central la perspectiva aglutinante del antifascismo para el reformismo y el comunismo. En sintonía, los trabajos Andrés Bisso (2007, pp. 23-63; 2005, p. 368) y de Bisso y Celentano (2006, pp. 235-266), también abonan esta línea de tratamiento. Específico para el CLES puede citarse Mabel Cernadas (2006, pp. 605-618).

2 Recordemos que la institución creó ocho cátedras con el objetivo de que cada una de ellas se convirtiese tanto en una alternativa al debate en los claustros universitarios argentinos del período, así como un ariete para la difusión del debate intelectual, científico y político en los medios académicos y el espacio público. La cátedra Domingo F. Sarmiento tenía como meta el estudio de temas educativos; la cátedra Alejandro Korn estaba dedicada a la filosofía. La aproximación a la literatura nacional tenía cabida en la cátedra Juan María Gutiérrez, los estudios jurídicos y políticos encontraban eco en la llamada Juan Bautista Alberdi, así como la cátedra Bartolomé Mitre estaba referida a temas históricos. Posteriormente se organizaron la Ca\#tedra de Estudios Brasileños y la Franklin Delano Roosevelt, dedicadas a la discusión americanista

3 ACe, Revista Cursos y Conferencias, Año IX, No 10, 11, 12, 1940

4 En el número 10 de su revista Cursos y Conferencias se informaba de las actividades que ya comenzaban a realizarse en Rosario. Tales actividades se iniciarían el 2 de mayo en la sede del Círculo Médico de Rosario previa inscripción. Esta no era tan solo una forma singular que adoptaría en CLES para su proyección institucional, sino que era algo común en la gestión de entidades que no disponían de presupuestos estables, y que subsanaba las dificultades funcionales y económicas. Archivo CEDINCI (ACe), Revista Cursos y Conferencias, 1(10), 447.

5 Las cuestiones relativas a las revistas literarias y culturales en Argentina han sido ampliamente trabajadas desde el campo de las letras y de la comunicación social. Tal tradición se refrenda en textos que desde fines de los años cincuenta intentan abordar las cuestiones inherentes a este tema [ver en especial Salvador (1962), Lafleur, Provenzano y Alonso (1968), Prieto (1968), Romano (1984), Rivera (1995, 1998), Manzoni (2004), Tarcus (2004).

6 Boletín del Colegio Libre de Estudios Superiores, Filial Bahía Blanca, mayo 1942. Cfr. López (2017, p. 121).

7 Las misiones culturales eran experiencias pedagógicas que propiciaban la interacción con el entorno, tanto el más próximo a la escuela -estableciendo vínculos con vecinos y transeúntes, en plazas, comercios y calles-, como el más amplio -constituido por referentes de la cultura letrada, y las artes-. También se interactuaba con referentes de asociaciones públicas y privadas. Un desarrollo inicial sobre el tema puede consultarse en Fernández, Guida y Welti (2011).

8 ACe, Revista Cursos y Conferencias, Año XVI, No 191-192, febrero-marzo/1948.

9 ACe, Revista Cursos y Conferencias, Año XVI, No 191-192, febrero-marzo/1948, pp. 261-262.

10 Memoria 1922/1924, Facultad de Ciencias Matemáticas, Físico Químicas y Naturales aplicadas a la Industria, UNL, 1925, p. 16; Serie Universitaria, Publicación N 49, Facultad de Ciencias Matemáticas, Físico Químicas y Naturales aplicadas a la Industria, UNL, 1950, p. 28.

11 Ángel Guido además fue en 1934 profesor titular de Urbanismo, y vicedecano de la ya mencionada facultad.

12 Guido, A. (1924). En defensa de Eurindia. La revista de "El Círculo, (otoño-invierno); Guido, A. (1924) Del Cuzco Colonia. La revista de "El Círculo, (otoño-invierno); Guido, A. (1925). Fusión hispano-indígena en la arquitectura colonial, Revista de "El Círculo", (otoño); y Guido, A. (1925). Creación de un instituto nacional de arquitectura americana. Revista de "El Círculo", (primavera).

13 Muchos tuvieron sus "viajes iniciáticos": el pintor José Sabogal pasó en 1918 de Tilcara a Cuzco, itinerario que consolidó de manera definitiva su inclinación indigenista; el viaje a Cuzco del arquitecto argentino Ángel Guido, junto a su hermano Alfredo y el escritor y político Alcides Greca en 1920...en México, Roberto Montenegro y Gabriel Fernández 
Ledesma parten con destino a Oaxaca, periplo revelador que dará origen a la Exposición Nacional de Artes Populares inaugurada en México en septiembre de 1921... como asimismo la labor de Fernández Ledesma en la revista Forma y de Diego Rivera en Mexican Folkways serán pilares de consolidación. Justamente para Rivera, Montenegro, Adolfo Best Maugard sería decisivo también el viaje que realizan a Uxmal y Chichén Itza en noviembre de 1921. En Brasil, José Marianno Filho y la Sociedad Brasileira de Bellas Artes patrocinan el viaje de Lúcio Costa a Diamantina en 1924...En ese mismo año, Oswald de Andrade y Tarsila do Amaral acompañan al poeta Blaise Cendrars a recorrer Minas Gerais, y quedan fascinados con el paisaje mineiro, la arquitectura barroca y la obra del Aleijadinho (Gutiérrez Viñuales, 2016, pp. 5-6).

14 ACe, Revista Cursos y Conferencias, Año 1, No 1, 1931.

15 ACe, Revista Cursos y Conferencias, Año 1, No 4, 1931.

16 ACe, Revista Cursos y Conferencias, Año 1, No 7, 1931.

17 ACe, Revista Cursos y Conferencias, Año 4, No 4, 1934, pp. 337-345.

18 ACe, Revista Cursos y Conferencias, Año 4, No 5, 1934, pp. 483-496.

19 ACe, Revista Cursos y Conferencias, Año 4, No 7, 1934, pp. 703-706.

20 ACe, Revista Cursos y Conferencias, Año XIII, No 147, 1944, pp. 127-137.

21 Fue uno de los jóvenes que ocuparon el edificio principal de esa universidad para asumir su conducción, conjurados en "dejar atrás el pensamiento medieval, dar la espalda a los falsos catedráticos y exigir verdaderos maestros que los condujeran por el camino de la verdad, única y universal”. Una fotografía de Plá, conducido detenido a la comisaría junto a otro rosarino, Ismael Bordabehere y los líderes reformistas fue esgrimida con orgullo por los estudiantes de la FCM en ocasión de cumplirse en 1938 el vigésimo aniversario de la Reforma. Suplemento de la Revista del Centro de Estudiantes de la Facultad de Ciencias Matemáticas de Rosario, cuarto trimestre, 1938, p. 25. Tomado de De Marco (2015, p. 44).

22 De Marco (2015, p. 50) describe en su texto que el relevamiento de 17 libros copiadores mecanografiados pertenecientes al decanato de la FCM del período 1934-1943 permite afirmar que no se detecta durante la gestión de Cortés Pla la intención de establecer oficialmente vínculos con facultades, institutos o centros de universidades españolas, lo que contrasta con las asiduas misivas dirigidas a los grupos de investigación de Estados Unidos, Brasil, Uruguay, Francia e Italia, en ese orden. En 1945, el mismo Plá afirmará delante de los profesores y estudiantes "que los claustros universitarios españoles estaban poblados por gente inferior intelectual y moralmente".

23 ACe, Revista Cursos y Conferencias, No 193-194, Año 1948.

24 Los títulos más significativos de Neuschlosz -ambos de 1939) son: Análisis del conocimiento científico y La medicina como ciencia y como actividad social.

25 En particular puede consultarse Karina Ramacciotti y Edmundo Cabrera Fisher (2010, pp. 153-176).

26 La conferencia de Simón Neuschlosz titulada “Bases físico químicas de los fenómenos vitales”, estaba programada para ser desarrollada entre mayo y agosto de 1931, en la sede el Círculo Médico de Rosario. ACe, Revista Cursos y Conferencias, Año 1, No 10, julio/1932, p. 447.

27 "Las dificultades conceptuales de la física moderna", ACe, Revista Cursos y Conferencias, Año VI, No 4, 1936; y "Los problemas filosóficos planteados por la teoría de la relatividad y la mecánica cuántica”, ACe, Revista Cursos y Conferencias, Año VI, 5, 1936.

28 Su militancia política en las filas de la UCR le permite acceder con solo 22 años a una banca como diputado provincial (1912) a partir del profundo conocimiento de los ciudadanos de San Javier, donde había sido Jefe Político. Reelegido en 1916 para el mismo cargo, sería elegido como diputado constituyente para la Reforma Constitucional Provincial de Santa Fe, y senador provincial en 1921. Es electo en dos oportunidades como diputado nacional por Santa Fe (1926 y 1930).

29 La obra es producto del viaje "iniciático" americanista que realizó junto a los hermanos Ángel y Alfredo Guido al Cuzco.

30 Sobre el análisis de la obra literaria ver Florencia Antequera (2017, pp. 107-134), y Daniela Greca (2015).

31 Un análisis sobre el particular puede encontrarse en Fernández (2000, pp. 191-219).

32 ACe, Revista Cursos y Conferencias, No 5-6, Agosto-septiembre, Año 1939.

33 ACe, Revista Cursos y Conferencias, No 5-6, Agosto-septiembre, Año 1939, p.432.

34 ACe, Revista Cursos y Conferencias, No 1-2-3, Abril-Mayo, Año 1941.

35 "Alabern y Fábrega compartían no solo la nacionalidad de origen, sino la condición de socios de la Bolsa y otras instituciones locales. En un momento determinado, dada la complementariedad de sus negocios, decidieron asociarse. Fue uno de los primeros canjes de esa época. Se entregaba la bolsa al productor agropecuario, este la llenaba de granos y el grano se vendía a través de Alabern y Compañía. La bolsa era el vehículo de la comercialización. Fue una alianza estratégica. Además, aquella relación estaba sellada por un sólido lazo familiar, ya que Fábrega contrajo matrimonio con una hija de Alabern" (De Marco, 2008, p. 52).

$36 \mathrm{Su}$ nacionalismo de matriz "euríndica", pero su posterior alineamiento con el gobierno de Juan D. Perón, que se manifestó primero en su designación como rector de la UNL y luego con la aprobación final de la construcción de lo 
Anuario del Instituto de Historia Argentina, noviembre 2019-abril 2020, vol. 19, nº 2, e099. ISSN 2314-257X

que es un símbolo ciudadano como el Monumento a la Bandera en Rosario, lo ligó de manera definitiva con el Partido Justicialista. 